\title{
Multi-Voiced Development in Finnish Early Childhood Education Practices
}

\author{
Jonna Kangas \\ Faculty of Educational Science, University of Helsinki \\ Helsinki, Finland \\ Tuulikki Ukkonen-Mikkola \\ Faculty of Education and Culture, University of Tampere \\ Tampere, Finland
}

\begin{abstract}
Early childhood education (ECE) is the first step of a lifelong learning pathway. In Finland, the institutions of ECE have went through many chances in recent years and the ongoing development of policies and practices of young children's educational system have been the focus of many projects and much research. In this paper researchers describe and analyse how dynamic development in regional development projects is implemented in teacher training programs, ECE field work and research in boundary spaces. The researchers describe the Finnish ECE system, its policies and practices to form a basis for the development project. Through that the basic principles of development are illustrated. The essential voices of participants of the project are introduced to form a picture of shared development goals, through opportunities and challenges, in multi-voiced community of education. Finally, the development work of ECE in the light of international knowledge of ECE is discussed. The findings of this research suggest that development in a multi-voiced community with different participators and organizations of the ECE can be successful and that the partnership approach can be development to create an active learning society of students, practical teachers and researchers.
\end{abstract}

Keywords: Development process; Teacher education; Early childhood education; Multi-voiced community; Partnership.

\section{Introduction}

During the recent years Finland, as many other countries, has tried to develop its' systems of early childhood education (ECE). In this development process in Finland some basic principles have been identified by researchers. The first principle is that ECE is based on academic teacher education, which provides a theoretical and practical basis for the pedagogy of ECE (Hujala 2008). Through 
high-quality teacher education developmental principles for pedagogy can be built through research-based knowledge which supports understanding and supporting the child's development. This also requires a strong and complex professional understanding which, according to Karila and Kinos (2012), can be divided into four types of relationships; the relationship with the children and parents, the work team and other expert groups. Therefore, Finnish ECE can be considered as multi-voiced (and multi-professional) educational environment where children's development and learning is supported. Venninen et al. (2012) have also shown in their research that ongoing learning and continuing education in teacher's profession is essential for the development of the Finnish ECE practices. The same finding occurs in a country report by the OECD (Taguma \& al. 2012) while educators' possibilities to develop their professional skills are supported in a national level. This ongoing learning requires multivoiced communities, where practical teachers of ECE (as the voice of the practical issues), university teacher and researchers (as the voice of theoretical knowledge) and teacher students (as the voices of the future) can share their experiences and conceptions about developing ECE and teacher education. In early childhood education this kind of co-operation and development between the working life and education have been rarely addressed in research, but examples of same kind of processes aiming to raise social work professionals understanding about academic knowledge for better decision making in practices have been studied by Gannon-Leary and Carr (2010) who argue that it is possible to create new culture of action where the theoretical knowledge becomes part of the practical decision making.

This research paper focuses on recent changes in Finnish ECE through the development project Seutuvarha which operates in both the academic teacher training program and the public ECE services. The aim of this paper is to analyse and describe how dynamic development in a regional project is implemented through multi-voiced communities. We focus on illustrating the forming processes through three basic principles of development. The voices of participants of the project have been found essential to form and work towards shared development goals. Therefore we adopt the narrative approach to describe existing challenges of the project from the perspectives of researchers, teacher students and the practical teachers in ECE.

The research questions are:

1. What kind of supporting structures do the participants experience in the multi-voiced communities of development?

2. What kind of preventing structures do the participants experience in the multi-voiced communities of development?

\section{The Finnish early childhood education context}

The Finnish national education policy guides the activities of ECE, as all other levels of the education system. (Ministry of Education and Culture 2019). The basic value is that everyone in Finland have equal possibility to participate to high-quality training and education. This provides state funded teacher 
education. The teacher training for ECE teachers is located in higher education faculties. The training is based on studies of the educational science and the approaches of sociology, childhood, psychology, cultural studies and many didactical contexts (e.g. literature, math, natural sciences and arts education). The qualification for ECE teachers is stated by law (The Act of Early Childhood Education 540/2018). The ECEC working team in the classes consists of three staff members; there is one teacher with Bachelor's or Master's degree and one to two assistant teachers with secondary level education degrees (see Kangas, Ojala, and Venninen 2015).

Finnish ECE is guided by two recently updated national documents, 'National core curriculum for early childhood education and care' (2018) and 'National Core Curriculum for Pre-primary Education' (2014). These normative documents obligate ECE professionals to the continuous and long-term development in the ECE organisations. This development process of ECE practices demands a reflective orientation in ECE communities. (See also Kangas \& al. 2019; Venninen et al. 2012).

The Finnish ECE is understood to consist support for children's wellbeing through care, education and teaching. This so-called "educare" model where learning through play has centre stage (see Leinonen, Ojala \& Venninen, 2015) is based on sociocultural learning framework where the development is seen as ongoing process of education, it is based on social interaction and it forms a mutual understanding about the goals and evaluation of development through social processes and interpersonal relationships and interaction between the educators, children, parents, administrators and researchers (National core curriculum for early childhood education and care 2018; Smith 1996). The ECE in Finland is based on high quality professional work by teachers. In their everyday work they observe children's development and skills, interact with children, design learning opportunities, evaluate activities and children's learning and finally reflect on their own professional skills, cultural routines of class and policy documents such as curriculums to develop the implementation of ECE pedagogy further (see Kangas et al. 2019; Karila and Kinos 2012; Ukkonen-Mikkola \& Fonsén 2018). The pedagogical activities are planned by teachers to provide all children equal opportunities in education, support sociability, and facilitate early intervention in learning difficulties. Overall, the goals of the Finnish ECE are to support the children's balanced development, growth, wellbeing and create the pathway for a lifelong learning. (National core curriculum for early childhood education and care 2018.)

\section{Seutuvarha - development through multi-voiced communities}

The goals of Seutuvarha project were published in spring 2012 as a starting point for the development work in ECE. Seutuvarha project aims to form a community of learners and researchers. New dialogic approach will be created through interaction between the theoretical and practical knowledge, where the development work will be shared. In education policies assumptions about learning transfer are often based on simplistic notions of research (Hager \& 
Hodkinson, 2009). Transferring academic knowledge to practices and, above all, evaluating this learning process through critical lenses requires, spaces for dialogue, both virtual and real meeting points (Gannon-Leary and Carr, 2010), where interaction can take place and where it will have support. The Seutuvarha project is viewed to be a community of research and development where teacher students, teachers from the ECE field, teachers and researchers from universities create shared knowledge and aims towards high quality learning and teaching practices.

One of the essential development principles was the idea of dialogic approach where the creating of knowledge is based on interaction between the participants. In this learning cycle different opinions and views meet in an open atmosphere (see Engeström et al. 1999). An important item in the successful development work is the participation of the members of society. In general participation means that each participant is respected and that they have an opportunity to become listened to and express opinions about the joint issue, through interaction and dialogue the participants can then create a learning culture of shared meanings (see Venninen et al. 2012).In the Seutuvarha project the development of teacher education is not the only seen as responsibility of the department of teacher education in the University. It is considered through political and social concepts about teachers' profession in the society and therefore the development is an issue for all the members of the ECE community. Lyra (2010) states that a multi-voiced dialogical approach creates opportunities that can construct the discussion for common perspectives and joint activity. Also, the development of ECE practices is seen as a dialogic process of all the participants. All these members of organizations also have their own goals for ECE work to negotiate with others. Also, Gannon-Leary and Carr (2010) have found the importance of shared informal learning processes, where they highlight the interaction between practitioners.

The development can be viewed as a joint activity of participants through a transformation of the practices and tools they use in everyday interaction, or through a transformation of the situation as opening up some possibilities for further action and same time closing others (Wells\& Claxton 2002). In the Seutuvarha project spaces for this interaction have been created in different occasions. These goals and working procedures are based on the dialogic approach where the development relies on the idea that the development process itself is the link between partners. Dialogue is, however, a complex phenomenon where multitude dimensions, both supportive and restrictive, can be identified. Constraints can be, for example, different conceptions of the phenomenon or varied working cultures (Lyra 2010). In the development processes it is essential to discuss about common goals for the process. The setting up of shared goals requires that both policies and participants' values, beliefs and conceptions about childhood, early learning and teaching are documented and discussed.

Virtual meeting points are essential for dialogue when there are not enough chances for all of the participants to come together to discuss. In this project the 
virtual meeting points were essential, because participants working in the field could hardly come together during the working days. Therefore, in the starting of the project a Seutuvarha blog was created as a place for dialog considering the developmental issues of the project. The blog was constantly updated with news about research findings, best practices of the field and themes of studies from both students and university staff. The possibilities of the online sharing have been found in research and development projects where the professional knowledge and practices were shared and developed online in multi-agency teams. Gannon-Leary and Carr (2010) state that "Web-based community networks create possibilities to share knowledge through online databases more efficiently updated than printed sources. Gannon-Leary and Carr (2010) highlight the possibilities of electronic networking between organizations and in the multi-agency working, but indicate that for functional development work 'New information tools are needed: they are likely to be electronic, portable, fast, easy to use, connected to both a large valid database of knowledge and the client record, and a servant of clients as well as practitioners.'

\section{Methods \\ Context of the Study}

This research paper focuses on the regional research and development project in the area of Tampere region called Seutuvarha (seutu from region and varha from varhaiskasvatus which means early childhood education). The Seutuvarha project started in 2012 and the main principle of the project is co-operation between University of Tampere (research and teacher training unit) and seven municipal ECE offices (producers of public early education services). Through these municipal ECE organizations the kindergarten teachers, other educators, managers of schools and especially the mentoring teachers have been participating in the project.

The project itself has been considered as a space for interaction between university teachers and researchers, teacher students (3 classes with 50-65 students) and six municipalities with 54 particular schools. The meeting points for participants have been created within the studies (for example theory based lectures for students and teachers from practice in the context of theory and research to bring their own experiences and conceptions into the shared discussion), in learning at work periods (where the responsibility of practical educational work with reflection is shared by student and practical teachers in interaction), in mentoring courses (where researchers and practical teachers meet to discuss and reflect the practices of scaffolding teacher students), in the context of research and development projects (where researcher observe ECE practices and policies and share their knowledge with practical teachers, administrators and students through lectures and writings) and in online platforms, such the e-learning courses for students and practice teachers and finally in a project blog to combine all the items mentioned above to be documented and discussed in an open-access environment. 


\section{Participants}

Seutuvarha participants were practical teachers of early childhood education working in the municipal kindergartens and pre-primary schools and participating in a course of mentoring practices. The course was organized twice during the school year. In first run there were 20 participants and in the second run there were 16 participants (see figure 1). Participants were also researchers and university teachers from Faculty of Education responsible of teacher education in early childhood education program. 4 of researchers were participating in the Seutuvarha practices. Finally students participating in their practical courses were also participants of Seutuvarha development. Total of 30 students participated in the research (see figure 1). All participants agreed to the terms of research and accepted to participate in interviews and focus-groups for research and developmental purposes.

\section{Data collection methods}

The focus of this research was to gain knowledge and understand the development structures in the Seutuvarha project through the voices of participating teacher students, ECE teachers and university staff. This approach considered participants as active agents who are capable of analyse and develop their work (Freire 2000) with a support of a facilitator - the researchers in this case - who participates in the development process and respect the participants as owners of their understanding and knowledge (see Kangas 2016; Edwards 2011; Fals-Borda \& Rahman 1991).

Data from the participants was collected during 2013-2015 through participatory approach methods where the researchers wanted to value the personal and shared experiences of participants. The data was collected from online discussions of practical teachers who work as mentors to teacher students, interviews of tutoring researchers, online students' forums during learning-atwork courses and from the Seutuvarha blog, where kindergarten teachers, researcher and students wrote their reflections about development of ECE practice, teacher education curriculum and learning at work (see figure 1). 


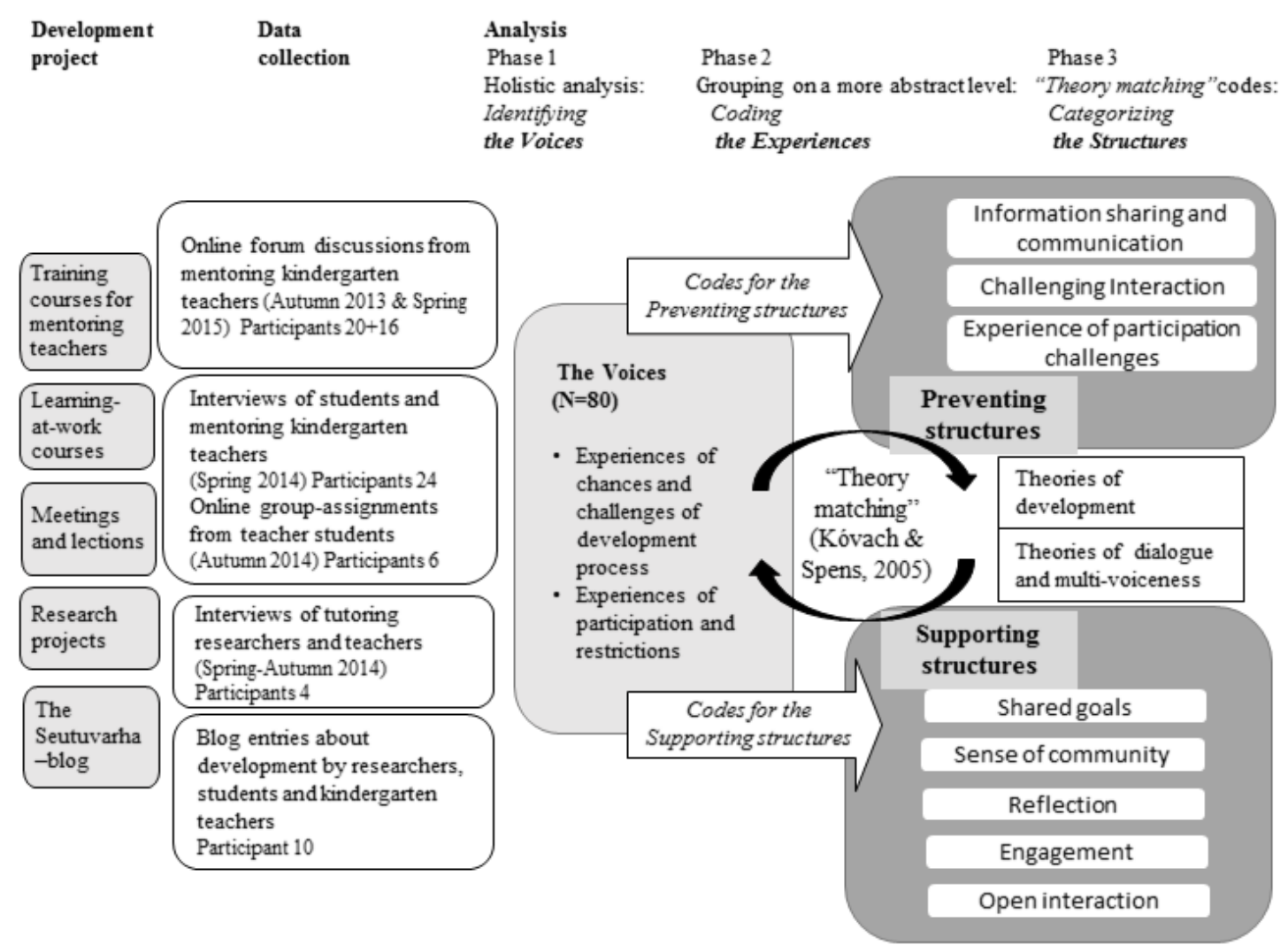

Figure 1. The process of data collection and analysis

The collection of data was complicated process because the researcher wanted to understand the perspectives of all participants throughout the development process during the year. Therefor the researchers adopted abductive approach for weaving all the different voices of development to examine shared goals and recognizing structures that prevented and supported the process. We will next introduce our analysis pathway.

\section{Framework for analysis}

This paper was conducted in an ongoing triangulation process between the authors. The first phase of analysis was based on content analysis in which the data was read through and challenging issues as 'meanings' considering ethical questions were identified. In the second phase, these meanings were considered through an abductive approach. Abduction as a research process can be viewed through intuition or as a kind of a systematized creativity in research to create 'new' knowledge (Kangas 2016; Andreewsky and Bourcier 2000).

In this research, the abductive approach was adopted to create new knowledge about the structures of development through and with the participating voices. With the abductive content analysis the identified challenges were discussed and evaluated based on the theoretical background in shared meetings of researchers. This process is called as theory matching by Kovách and Spens (2005) and in this research it aimed to recognize the supporting and preventing structures of development by multitude voices of participants (see figure 1). Founded structures of development were discussed and critically evaluated 
through the triangulation process of the researchers. Research triangulation was conducted to ensure that the analysis was based on valid understanding and previous knowledge (Kangas \& al. 2019; Golafshani 2003). The triangulation between the researchers was essential in the abductive analysis cycle and through it the understanding about development was created, interpreted and reproduced through several cycles.

\section{Limitations of the research}

There are some limitations concerning the validity of this research. One possible limitation is that the data were collected during practical courses and in-serviceteacher training at the university. The researchers' commitment to organising these activities and relationships between participants and researchers can affect negatively the objectivity and validity of the data collection and the whole study. (see Atkins and Wallace 2012). However the triangulation process explained above was used to gain objectivity to findings and work through reflective practice towards the validity of the research (Ojala \& Venninen al. 2011; Golafshani 2003).

\section{Findings}

In the next chapter we bring up the voices of the participants considering the experiences and understanding of structures in Seutuvarha-development project.

\section{Voice of teaching practices - the teachers}

Mentoring teachers brought up satisfaction of co-operation between university and working life. In first quote states, that mentors are engaged to co-operation and in second quote representative of ECE appreciate the possibility of cooperation.

"This is quite new in our school. I think, that we are very engaged and want to develop this co-operation with university."

"It is so important, that surrounding municipalities and schools have become involved in this co-operation."

The teachers also indicated the meaning of excitement and motivation of participating in the project. They stated that they felt proud to be involved in the teacher education processes and get in-service teacher training to understand and implementing in the practice scientific findings and through them the future of ECE practices. Representatives of ECE field emphasized that they can benefit from the co-operation.

"Mentors are trained about how to instruct students. Participating in [university courses] also helps for understanding other matters...gives positive resource to the field work."

Mentoring kindergarten teacher brought out, on the other hand, the importance of getting to know future kindergarten teachers' while they still were students. They explained how important it is to know and participate the discussion about the education of teacher student to shape the future ECE: 
"...it is possible to meet students through this project... in the future it means that we get also new employers.'

'I feel strongly, that we teachers get the most benefit [from this project].

We get to know how future kindergarten teacher are trained and what important [knowledge] is."

During the project participants have had chances to reflect on their own work. In this quotation critical observations have been done by one of the mentoring teachers. The second quotation continues from where the first ends to reflect also the pedagogical work done with children.

"Yes, what was now read in this feedback...the importance of interaction between mentor and students. It is never too old idea. Dialogical interaction is very important..."

"And there are still many challenges in our pedagogical work [with children]. It is worth in a group [of mentors] to think a little that how we are doing these [everyday] matters, these routines."

One of the goals of Seutuvarha project was research and developmental cooperation. It was valued, but mentioned, that it has been quite marginally used during the past year. In the next quotations bring up this matter.

"I don't now suddenly remember anything. It can be also in small-scale, but I think, it is very important part of... so we can be with this development.'

'So, I hope at least, that it (research and developmental work) would be... that it has been perhaps limited during this spring."

The teachers used the Seutuvarha blog for reflecting on their learning experiences considering the group learning activities of mentor training and mentoring. Some of them also shared writings about their best ECE development practices and commented others development ideas, like in these quotes:

"...the pedagogical planning is shared activity with children, and it could start from everyday chatting where child brings out his interest." "So wonderful observations! It has been interesting to read your ideas...my thoughts [about the development] have strengthened and I have got new ideas to explore with students!"

However, reflection in the e-learning platform was considered challenging. The teachers found it problematic to find time to document and to share their experiences online and they have a lack of ICT skills. On the other hand they find it important to read others experiences: "So little time to read and write responses at the computer. So much to tell...!"

Voices of the theoretical knowledge - the researchers

Tutoring researchers from University have been analysing their role through scaffolding approach, like in this quotes below where researchers describe their goals about the meetings in schools during students' learning at work courses:

"I wish I could scaffold teacher students learning in practice, also support their mentoring kindergarten teachers working in the field of 
ECE in their reflections... Routines and fixed activities could be reflected and new ways of practices could be learned..."

"[The tutoring practice of students' in-service training] have helped me to belief in my competence of scaffolding (instead of teaching) students to aim towards professional identity of kindergarten teacher."

Some researchers emphasized that with dialogic approach, the learning process could be viewed as a shared and ongoing process of social understanding, rather than a cognitive process of the student.

"...thus the experience of learning could be shared among the three of us, because the students coming to school can be a starting point of a process where ECE practices are re-evaluated.

"Sometimes the meetings have emphasized a chain reaction, where my theory based critical reflection have evoke deep dialogue between mentor and the student, where through the discussion a process of reflection has become deeper. For me, it seems, the reflective thoughts have been already in the minds of all participants, but they require few outspoken questions..."

Tutoring researchers also reflected the dynamic process of developing professional knowledge in the boundary work of theory and practice. Here is an example of those reflections. The first quote emphasizes the idea of a shared learning process, while the second brings out the new knowledge she found to have emerged during the meetings:

"I have sometimes experienced that the level of reflection between the teacher student and the practical teacher have been...the student and the mentor have been in equal positions to discuss and reflect the practices and the knowledge in joint discussion."

"... I noticed to be a participant of meaningful and productive discussion between professionals: teachers, students and researchers. The key elements of these discussions were sharing, brainstorming, designing, critical reflection and finally, forming conclusions that would really have influence in the practices"

Researches felt that one problematic area in the project was sharing the information and communication between all actors. This required time and resources from the researcher and also new practices for the information processes:

"This is very valuable message for us from students, that this information sharing is one very important development task still to achieve."

The researchers used the Seutuvarha blog for sharing information about new research findings and the goals and practices of ECE studies in university. The blog worked as platform for announcing agendas and schedules of courses, meeting and surveys. They also wrote about experiences about involving tutoring and teaching processes like in this quote: 
"This assignment seemed to be meaningful both as theoretical learning task and practical teaching experience. Students really engaged in the task and results were produced for us all to read."

\section{Voices of the future - the students}

The representative of the students thinks, that the project is an important possibility of learning in the boundary spaces and for improving knowledge by learning through practices and theories:

"I belief that the project creates opportunities to develop my professionalism. I can have experiences and knowledge through the field work. I can be member of the school community and I can learn from the theories."

Well educated and competent mentors are considered significant among students. Students have noticed, that mentors have a remarkable effect on the learning of the students during learning at work period. The first quote refers on the evaluation of the project and on students learning opportunities, while the second quote focuses on the interaction between students and the mentors:

"That we, students, feel wonderful here to study, while we have the possibility [to participate] in this kind of Network of kindergartens practice. Because then again if I had to go to the field without this kind of mentoring, it will be pretty harsh and somehow feeling insecure to go there. So, it is a fine opportunity."

"One of the important issue that support my learning was that my mentor trusted me and treated me as equal...my opinions were taken account."

Students also found preventing experiences with the multi-voiced community. Many of them thought that even if their mentor gave them support and was open for dialogue, the other members of the field work community were not:

"My role in the school community was very contradictory. When I was ready to take responsibility with mentor's permission, some other worker involved in and take the responsibility from my behalf. I felt like an assistant."

Students found controversial issues considering the use of e-learning platforms and the blog for reflection. On the other hand they felt that an e-learning platform supported mobility in documentation and reflection. On the other hand e-learning and social media require competence that all of the students didn't have. A student commented: 'I chose to apply for teacher education because I want to work with people, not with computers'. It seems that among the students the meaning of media as a space for shared learning, meaning-making and reflection is not yet recognized. The students used the Seutuvarha blog for sharing their experiences of studies both in theory and in practice and their learning reflection like in this quote:

"In the learning at work course we have had an opportunity to...get involved in a project of enhancing children's participation...in a pedagogical evening meeting...small groups of teachers were chatting about existing practices that support participation and pondering what 
practices there will be needed. During the meeting all the participants agreed that a big poster of identified participation experiences of children will be put up in the wall."

\section{Concluding of the results}

In a community like the Seutuvarha project the dialogic approach becomes complex, because the development cannot occur only between educators or researchers, but the children, their parents, and teacher students, whose viewpoints about the goals and practices of ECE are based on different approaches and experiences. Based on the voices of all participants (practical teachers, students, university teachers and researchers) many features of a multivoiced community and also supporting and preventing practices for development can be found.

\section{Supporting structures of development in multi-voiced community}

Interaction between the Seutuvarha-participants is open, as well as successes and challenges are discussed during in-service teacher training. Lyra (2010) notes that precondition to dialogue is that both supportive and preventive dimensions can be identified. Participants are engaged to Seutuvarha-project. University researchers, practical teachers and students are committed to development work. They all believe, that this encounter of theory and practice benefits all participants to develop their work. The Seutuvarha blog had the role of a platform of shared experiences and reflection for all the voices in the project. These experiences are common for all participants, furthermore there are some different experiences between various actors in project.

Students appreciate that kindergarten teachers were trained to work as mentors by the university teachers and researchers as part of the project. Thus students experienced that the teachers understood their learning goals and they could participate as members of ECE society during learning at work periods, and they also felt that mentors trusted them and listened to them as equals. As discovered also by Press, Sumsion, and Wong (2010) the possibilities for participation and opportunities to become listened to through interaction and dialogue are important features in development work.

Practical teachers valued the sense of community, they felt that ECE society of Tampere was constructed during Seutuvarha-project. This sense of community offers possibilities to create a multi-voiced learning culture and to produce shared meanings with other participants and organizations (see Venninen and al. 2012). Through the community of learners it was possible to get to discuss and understand differences of ECE working cultures (see Lyra 2010) and also new theoretical knowledge of learning and teaching. Municipalities of Tampere region were enthusiastic to have teacher students in their schools for inspiring practical teachers to evaluate their own pedagogical work and through this to raise the quality of pedagogy. Furthermore, learning at work periods were considered a chance to recruit future employees. 
University teachers and researchers experienced that meetings in the field gave opportunities for reflective discussions with mentors and students. They felt that theoretical reflections have emerged in the dialogue between mentor and student, while some reflection was deeper. Also, Ojala and Venninen (2011) have shown that reflection about practices in ECE field deepens when teachers experience participation in development projects. The researchers of Seutuvarha-project also brought out their growing competence of scaffolding students' professional identity as a future teacher during their studies. They believed, that sharing critical reflection and forming conclusions influenced the practices both in the field and in the university.

\section{Preventing structures of development in multi-voiced community}

Preventing practices of development in a multi-voiced community can be recognized from the voices of Seutuvarha-participants. The project has focused on interaction and development around learning at work periods and, for example, the research findings got less attention. Also information sharing and communication between actors has been problematic, though many information channels, such as e-mail, phone, papers, blog announcements and face to face meetings, were at use. The Seutuvarha blog, even when it worked as a platform of sharing experiences, lacked online interaction between the participants. The voices were interested to share their own, but not to discuss others experiences. Both lack of research and developmental work and problems concerning discussion and communication had been noticed and all participants are willing to develop these practices.

Furthermore, teamwork and interaction are perceived as preventing practices for development. Some students felt, that teams in schools were not ready or aware to give responsibility to students. Interaction can sometimes be very challenging and misunderstandings can happen between actors. Press and al. (2010) emphasize that, for a development process to succeed, the participants must be listened to, have a dialogue between practical experiences, and be committed to the development process also as a school community. These elements have been a challenge in Seutuvarha project because most of the reflective discussion have been ongoing between teacher students and their mentoring teachers through learning at work periods, or between the researchers and students in university courses. These discussions have been experienced as being important (as shown in the Voices of participants' chapters), but the whole ECE community has not yet had changes to meet and discuss about the development. The main reason for this is that schools cannot be closed during the development days, and thus the information and ideas of development need to be transferred to the educators in the schools or to the students in the university. As shown by Ojala \& Venninen (2011) development in ECE field is problematic because not even the team members of class have the time for meetings and for reflecting on the ongoing processes (see also Venninen \& al. 2012). 


\section{Discussion}

The goal in this development process has been a multi-voiced and dynamic approach for development which is found to be essential to support getting all members of the development process to participate. While the benefits of development projects are realized, it is not certain that they are adopted and participants regress to earlier practices. Wells and Claxton (2002) state that the development of an organization happens collaboratively with other participants and is the main principle for changing the culture. Even while the benefits of the Seutuvarha project are certain, the challenge is in supporting participants in adopting the ongoing development in a multi-voiced community as their working principle. The dialogical approach creates opportunities for negotiation and thus clarifying and strengthening conceptions and through that beliefs about shared items of development (see Brownlee, 2009). As brought out by all of the voices of this process, the status together with inner beliefs about learning of each participant was causing controversial issues. In this kind of development process it is essential that all the voices have equal opportunities for participation and spaces for dialogue are openly created. In the Seutuvarha project the structures of the development practices are now created, but for continuity more open and involving practices need to be created. It has been shown by Ojala \& Venninen (2011) that different personal epistemologies lead to different teaching practices, for example evaluative personal epistemology was likely to lead to constructivist approaches to teaching.

With a life-long-learning approach the development project of ECE should be connected to the larger scale of educational reform. ECE should not be considered as an isolated area of education and care, but as parts of life-longlearning pathways where children and adults who work with them learn together and create shared knowledge through the interpretative reproduction (see Corsaro 2011). This requires that the research and policies recognize the voice of practice and respect it. Ammentorp and Madden (2014) have found in their research of teacher training that peer-related co-operation between ECE teacher student created concepts and skills such as problem solving, reflection, self-regulation and purposefulness. We suggest that this kind of a partnership can be considered through wider approach to become an active learning society of students, field working teachers and researchers from the different points of educational pathways. The partnership based on a sense of community education system as a learners' community as the new Curriculum Reform of Finland (2016) states - could be the ideal starting point of a development project like this. Malinen (2015) states, that a sense of community can be identified in networks with unknown people. The participants wrote informative texts to the blog, but did not start the online discussions. We suggest that the reason for this might be found in the participants' status and roles. The mentoring kindergarten teachers and the university researchers, who could have started the commenting and discussing seemed to lack resources (time, computers) and social media skills, and students, who had resources and skills don't dare to be the first commentators, because they felt their role was not equal to that of the teachers. Gannon-Leary and Carr (2010) note the benefits of availability of up-to-date online information, but state also the when participant have lack of the skills to use it effectively in the development projects, 'more attention must be paid to 
the context of learning use'. For example, in the future digital spaces might be used for larger scale development of communities of learning also in ECE, if the discussion platforms could be composed to be more involving and more dialogic from the starting point.

\section{Conclusion}

The aim of this research paper has been to describe and identify the role and voices of a multi-voiced community in development of ECE in dialogical cooperation between the teacher training program, the teachers and researcher and the practical field work of early childhood education. In Finland the quality of ECE teacher education has been considered to be of a high level, because of academic teacher training traditions providing research-based knowledge about understanding the learning and development in early years (Hujala 2008). Internationally high quality of ECE have been linked in academic teacher education. However, as the Seutuvarha project has shown, the theoretical knowledge is not enough when field workers - current and future teachers have to cope with changing understanding about childhood and society. For example Konkola et al (2007) highlights the meaning of teachers, students and practitioners' possibility to co-operate at the space that is free from routines and rigid patterns. Therefore it is important that in the practices and theories of education, there is space for open dialogue with shared development goals. This creates opportunities for critical reflection and thus supports the development of high-quality ECE, as the results of this study indicate. High-quality educational practices and policies are not standards to be copied from other organizations or institutions, they emerge through processes of ongoing reflection and development in the socio-cultural settings of ECE. This requires that ECE teachers have academic qualifications from teacher training programs, where professional knowledge is formed and critically evaluated within the boundary spaces of theory and practice. Teacher students' competence of professional skills and knowledge of education, childhood and socio-cultural issues are essential to scaffold in multi-voiced community of themselves, teachers and researchers. The developing of co-operation between the ECE field services, schools and universities have been evaluated by Balduzzi and Lazzari (2015). The results of this kind of partnership are encouraging: the strong partnership between academic research and education generate reciprocal benefits, even sustaining and producing pedagogical innovation. Nolen et al. (2011) has stated that in experiences of conflicts as productive frictions are essential to creating learning opportunities for teacher students. We think that in the development process a multi-voiced community can experience - and should experience these productive frictions, because they contribute to a new kind of dialogue between the participants, where the process of development and experiences about it are more important than the outcome. Positive outcomes of the development project can also be noticed from the current situation of the project. Since 2016 the project has become established operation between municipalities and university under the Early Childhood Education Network title. Despite of many challenges of Seutuvarha project, the positive outcomes of the development can be quoted through voice of the participant: 
"Yes, this is improving the overall quality of early childhood education. It's excellent, that this university knowledge is applied to the wider province."

\section{References}

Act of Early Childhood Education 540/2018 (2018). Ministry of Education. Finland.

Andreewsky, E., \& Bourcier, D. (2000). Abduction in language interpretation and law making. Kybernetes 29(7/8), 836-845. https:/ / doi.org/10.1108/03684920010341991

Ammentorp, L., \& Madden, L. (2014). Partnered Placement: Creating and Supporting Successful Collaboration Among Preservise Teachers. Journal of Early Childhood Teacher Education 35(2), 135-149. http://dx.doi.org/10.1080/10901027.2014.905805

Atkins, L., \& Wallace, S. (2012). Interviewing in educational research. In L. Atkins \& S. Wallace (eds.). Qualitative research in education. SAGE publications.

Balduzzi, L., \& Lazzarri, A. (2015). Mentoring practices in workplace-based professional preparation: a critical analysis of policy developments in the Italian context. Early Years: An International Research Journal 35(2), 124-138. http:/ / dx.doi.org/10.1080/09575146.2015.102251

Brownlee, J. (2009). Context, Pedagogy and Participatory Learning. In: D. Berthelsen, J. Brownlee, and E. Johansson (eds.), Participatory learning in the early years: research and pedagogy, (pp. 203-208). New York: Routledge.

Corsaro, W. A. (2011). The sociology of childhood. Thousand Oaks, CA: Pine Forge Press.

Curriculum Reform of Finland (2016). Retrieved from Rehttp://www.oph.fi/english/education_development/current_reforms/curri culum_reform_2016

Gannon-Leary, P., \& Carr. J. (2010). New partnerships for learning: meeting professional information needs. Journal of Education and Work 23(1), 65-77. http:/ /dx.doi.org/10.1080/13639080903495129

Edwards, A. (2011). Building common knowledge at the boundaries between professional practices: Relational agency and relational expertise in systems of distributed expertise. International Journal of Educational Research 50(1), 33-39. http://dx.doi.org/10.1016/j.ijer.2011.04.007

Engeström, Y., Miettinen, R., \& Punamäki, R. L. (1999). Perspectives on activity theory. Cambridge University Press.

Fals-Borda, O., \& Rahman, M. A. (1991). Action and knowledge: breaking the monopoly with participatory action-research. Apex Press.

Freire, P. (2000). Pedagogy of the oppressed. London: Bloomsbury Publishing.

Golafshani, N. (2003). Understanding Reliability and Validity in Qualitative Research. The Qualitative Report 8(4), 597-606. Retrieved from https://nsuworks.nova.edu/tqr/vol8/iss4/

Hager, P., \& Hodkinson, P. (2009). Moving beyond the metaphor of transfer of learning. British Educational Research Journal 35(4), 619-638. http://dx.doi.org/10.1080/01411920802642371

Hujala, E. (2008). The Development of Early Childhood Education as an Academic Discipline in Finland. Nordic early childhood education research journal 1(1), 17-23. http://dx.doi.org/10.7577/nbf.238

Kangas, J., Harju-Luukkainen, H., Brotherus, A., Kuusisto, A., \& Gearon, L. (2019). Playing to Learn: Early Childhood Curricula Contexts from Finland. In: S. Garvis \& S. Philipsson (eds.) Policification of Childhood: Early Childhood Education in the 21st Century. (pp. 110-127). London: Routledge 
Kangas, J. (2016). Enhancing children's participation in early childhood education through participatory pedagogy. Doctoral dissertation. Helsinki: University of Helsinki.

Kangas, J., Ojala, M., \& Venninen, T. (2015). Children's self-regulation in the context of participatory pedagogy in early childhood education. Early Education and Development 26(5-6), 847-870. http://dx.doi.org/10.1080/10409289.2015.1039434

Karila, K., \& Kinos, J. (2012). Acting as a professional in a Finnish early childhood education context. In L. Miller, C. Dalli, \& M. Urban, (eds.) Early childhood grows up. Towards a critical ecology of the profession, 55-69. London: Springer.

Konkola, R., Tuomi-Gröhn, T., Lambert, P., \& Ludvigsen, S. (2007). Promoting learning and transfer between school and workplace. Journal of Education and Work 20(3), 211-228. http://dx.doi.org/10.1080/13639080701464483

Kovács, G., \& Spens, K. M. (2005). Abductive reasoning in logistics research." International Journal of Physical Distribution \& Logistics Management 35(2),132-144. http://dx.doi.org/10.1108/09600030510590318

Lyra, M. C. (2010). On interaction analysis and dialogical perspective: emergent patterns of order and relational agency. Integrative Psychological and Behavioral Science 44(3), 273-280. https:// doi.org/10.1007/s12124-010-9130-y

Malinen. S. (2015). Sociability and Sense of Community among Users of Online Services. PhD dissertation, University of Tampere: Finland.

Ministry of Education and Culture, Finland (2019). Retrieved from: https://minedu.fi/en/ministry

National Curriculum of Early Childhood Education and Care. (2018). EDUFI - Finnish National Agency for Education.

National Core Curriculum for Pre-primary Education (2014). EDUFI - Finnish National Agency for Education.

Nolen, S. B., Horn, I. S., Ward, C. J., \& Childers, S. A. (2011). Novice teacher learning and motivation across contexts: Assessment tools as boundary objects. Cognition and Instruction 29(1), 88-122. https://doi.org/10.1080/07370008.2010.533221

Ojala, M., \& Venninen, T. (2011). Developing reflective practices for day- care centres in the Helsinki Metropolitan Area. Reflective Practice: International and Multidisciplinary Perspectives 12(3), 335-346. http://dx.doi.org/10.1080/14623943.2011.571865

Press, F., Sumsion, J. \& Wong, S. (2010). Integrated early years provision in Australia. Bathurst, NSW: Charles Sturt University.

Smith, A. B. (1996). The early childhood curriculum from a sociocultural perspective. Early Child Development and Care 115(1), 51-64. http://dx.doi.org/10.1080/0300443961150105

Taguma, M., Litjens, I., \& Makowiecki, K. (2012), Quality Matters in Early Childhood Education and Care: Finland 2012, OECD Publishing, Paris, https://doi.org/10.1787/9789264173569-en

Ukkonen-Mikkola, T., \& Fonsén E. (2018). Researching Finnish early childhood teachers' pedagogical work using Layder's research map. Australasian Journal of Early Childhood 43(4),

48-56. https://journals.sagepub.com/doi/10.23965/AJEC.43.4.06

Venninen, T., Leinonen, J., Ojala, M., \& Lipponen, L. (2012). Creating conditions for reflective practice in early childhood education. International Journal of Child Care and Education Policy 6(1), 1-15. http://dx.doi.org/10.1007/2288-6729-6-1-1

Wells, G., \& Claxton, G. (2002). Introduction: Sociocultural perspectives on the future of education. In G. Wells, and G. Claxton, (eds.) Learning for life in the 21st century, (pp.1-18). Oxford: Blackwell Publishers Ltd. 